\section{Vaccines should be kept even if polio is wiped out}

Sir - We would like to clarify a point in your News story (Nature 418, 265; 2002) about our report of the chemical and biochemical synthesis of poliovirus (J. Cello, A. V. Paul \& E. Wimmer, Science 297, 1016-1018; 2002). The World Health Organization (WHO) is considering terminating polio vaccination after global eradication has been certified, when wildtype polioviruses would no longer be circulating in the human population. But the WHO is also formulating plans to stockpile vaccines in case an outbreak occurs after termination, caused by viruses that had been undetected during the eradication campaign. We suggest stockpiles should be maintained indefinitely if vaccination against polio is terminated. Jeronimo Cello, Aniko V. Paul, Eckard Wimmer

Department of Molecular Genetics and Microbiology, School of Medicine,

State University of New York at Stony Brook, Stony Brook, New York 11794-5222, USA

\section{Arp2/3 plays no role in muscle contraction}

Sir - We are pleased that Arp2/3 complex was included as an example in your News Feature "The society of proteins" (Nature 417, 894-896; 2002). However, to the uninitiated reader it might appear that Arp2/3 complex is involved in muscle contraction. Although it participates in the assembly of actin filaments at the leading edge of motile cells, we want to clarify that it has no known role in muscle in either the assembly of actin filaments or contraction. Thomas D. Pollard ${ }^{\star}$, Dorit Hanein $\dagger$, Niels Volkmann $\dagger$

*Yale University, KBT 548, New Haven,

Connecticut 06520, USA

$\dagger$ Burnham Institute, 10901 North Torrey Pines Road, La Jolla, California 92037, USA

\section{Seeing stars}

Sir - Your Opinion article "Save starry nights" (Nature 418, 709; 2002) advocates control of public lighting to prevent a lack of starlight diminishing the quality of citydwellers' lives. As you point out, someone in Venice can look up and see all the stars in the constellation of Ursa Minor, but this would be impossible for people in most other cities from New York to Sydney.

Reduction of light pollution may, indeed, help New Yorkers to see these stars. People in Sydney, however, will still have to go to a planetarium to see Ursa Minor, as they live in the Southern Hemisphere.

Rob A. Gruters

UMR2142 CNRS/bioMerieux, ENS de Lyon, 46 allée d'Italie, 69364 Lyon Cedex 07, France

\section{Thriving UCSF needs all the space it can get}

Sir - You state in a News story (Nature 418, 355; 2002) that "biotech firms are turning down the chance to move into premises on a top university campus". The concept that this university site is unattractive to companies is central to this article and is implied by the headline.

The University of California, San Francisco, (UCSF) is not seeking companies to move onto our property. We need every square foot we can get for our own laboratories at our new 43-acre research and teaching campus at Mission Bay. There is no \$85-million commercial site vacant on UCSF property as stated in your article, nor will there ever be.

Your article confuses the Mission Bay campus with an adjacent 300-acre site owned by Catellus, a real-estate developer. UCSF's site is proceeding spectacularly, with buildings worth more than $\$ 800$ million either under construction or in the planning stages. Attracting companies to the Catellus site is a marketing issue for the privately owned biotechnology park.

Regis Kelly

Executive Vice Chancellor, UCSF,

513 Parnassus Avenue, Room S-101,

San Francisco, California 94143-0407, USA

This story was edited for space reasons, cutting out a statement that UCSF's development and the adjacent commercial one are being managed separately — News Editor, Nature.

\title{
Efforts to revive Serbian science
}

\section{Members of the 'old guard' remain in power and are hindering moves to change a demoralized culture.}

Sir - Since the overthrow of Slobodan Milosevic's regime, many efforts have been made to revitalize Serbia's ruined society. Milosevic's rule was particularly detrimental to science, which was devastated both in manpower and in financial resources. Most top scientists have left the country, and investment in basic research has been reduced to the most dangerous level yet (for example, see Nature 394, 715; 1998 and Europhys. News $30,4 ; 1999)$. What is the the standing of fundamental research in Serbia now?

The new Ministry for Science, Technology and Development has been trying to remedy the misdeeds of the previous regime, but the resistance of the 'old guard' is still very powerful. Conflict between the ministry and scientific institutions has resulted in disagreement about the percentage of the gross national product to be allocated to the sciences. One of the latest proposals is $0.21 \%$, a decrease of $37 \%$ for fundamental science research. The dilemma is whether a poor country like Serbia should try to reach the developed countries' goal of $1 \%$, which, according to our basic-research institutions, is necessary to perform internationally competitive work. Or should it concentrate on applied research, as the new minister of science advocates?

Another important issue for basic science, in the context of very limited resources, is whether to continue doing research at specialized institutes (the practice until now) or move it to universities, as in the United Kingdom and elsewhere.

This question was due to be discussed at the Debate Tribune at the Institute of Physics, Belgrade, on 25 June, but the debate was cancelled by management for fear that the truth about the situation would come out. The truth is that many research institutes are functioning at less than half capacity because employees are running private businesses, or are engaged in other nonscientific activities, while retaining their scientific posts even though they do not turn up for work regularly. Nobody has been removed from projects or fired for this corrupt practice, which is becoming widespread. This is why some people advocate placing fundamental research, which is hard to control administratively, in universities, where staff earn their pay by teaching even if they neglect their research activities.

But the principal problem is psychological. After 15 years of despair and demoralization, it is not easy to persuade people to return to their professional duties. In particular, many institutes are run by people who came to power during the Milosevic era, and it will probably be another generation before Serbia is decontaminated in this respect. Petar Grujic

Institute of Physics, PO Box 57, 11080 Belgrade, Serbia, Yugoslavia 